\title{
TECNOLOGIA Y MOVILIDAD EN EL ATUEL MEDIO: EL REGISTRO ARQUEOLOGICO DEL SITIO LOS GALLEGOS 1 (SAN RAFAEL, MENDOZA)
}

\section{TECHNOLOGY AND MOBILITY IN THE MIDDLE ATUEL: ARCHAEOLOGICAL RECORD OF THE LOS GALLEGOS 1 SITE (SAN RAFAEL, MENDOZA)}

\author{
Nuria Sugrañes ${ }^{1}$, María de la Paz Pompei², Gustavo Neme³, Adolfo Gil ${ }^{4}$ \\ ${ }^{1}$ Instituto de Evolución, Ecología Histórica y Ambiente; Av. Urquiza 315, San Rafael, Mendoza; \\ Argentina. Email: nuria30@gmail.com \\ ${ }^{2}$ Instituto Superior de Estudios Sociales, CONICET - UNT; San Lorenzo 429 (4000), San Miguel \\ de Tucumán, Tucumán; Argentina. Email:paz.pompei@gmail.com \\ ${ }^{3}$ Instituto de Evolución, Ecología Histórica y Ambiente; Av. Urquiza 315, San Rafael, Mendoza; \\ Argentina. Email: gneme@mendoza-conicet.gob.ar \\ ${ }^{4}$ Instituto de Evolución, Ecología Histórica y Ambiente; Av. Urquiza 315, San Rafael, Mendoza; \\ Argentina. Email: agil@mendoza-conicet.gob.ar
}

Presentado: $14 / 06 / 2020$

Aceptado: 30/11/2020

\section{Resumen}

En el presente trabajo se evalúan las tendencias tecnológicas de los conjuntos líticos y cerámicos del sitio arqueológico Los Gallegos 1, localizado en el valle medio del río Atuel. El objetivo principal es explorar las estrategias de movilidad y modos de ocupación durante el Holoceno tardio final en la región de Monte, al sur de la provincia de Mendoza. Los resultados muestran que el sitio fue un campamento residencial donde se realizaron actividades múltiples. Las evidencias tecnológicas señalan una baja movilidad residencial de los grupos humanos que ocuparon este espacio hacia fines del Holoceno tardío (ca. 1082 años cal. AP), y que su emplazamiento priorizó la cercanía al curso de agua del río Atuel.

Palabras clave: Mendoza, tecnología lítica y cerámica, movilidad humana, Holoceno tardío

\section{Abstract}

In this work, we evaluate the technological trends of the lithic and ceramic assemblages of the Los Gallegos 1 archaeological site, located in the middle valley of the Atuel River basin. The main objective is to explore mobility strategies and occupation during the late Holocene in the Monte region in the south of Mendoza province. The results show that the site was a residential camp where multiple activities were carried out. Technological evidence indicates low residential mobility of the human groups that occupied this place towards the end of the late Holocene (ca. 1082 years cal. AP), and where their location prioritized proximity to the Atuel River. 
Keywords: Mendoza, lithic and ceramic technology, human mobility, late Holocene

\section{Introducción}

Las estrategias de movilidad de los grupos humanos tienen una estrecha relación con las características ambientales donde estos desarrollan sus actividades (Binford 1980; Kelly 1992). Su abordaje desde la arqueología ha sido realizado desde distintas líneas de evidencia y con diferentes grados de resolución (Bamforth 1986; Beck 2009; Beck et al. 2002; Eerkens 2003; Jones et al. 2003; Kelly 1992; Pallo y Borrero 2015). En el Centro Oeste Argentino, los estudios sobre movilidad han sido enfocados a partir de las fuentes de obsidiana (Cortegoso et al. 2012; Durán et al. 2004; Giesso et al. 2011; Salgán et al. 2015), zooarqueología (Neme et al. 2013), de isotopos estables (Gil et al. 2011) y, recientemente, desde la cerámica (Lagiglia 1997; Sugrañes 2011; Sugrañes et al. 2020). Sin embargo, dichos trabajos han abordado de manera secundaria esta discusión en el área del Atuel medio, especialmente por la escasa cantidad de sitios arqueológicos analizados de manera integral en estos espacios.

Particularmente, el sur de la provincia de Mendoza posee una heterogeneidad ambiental característica que ha sido abordada arqueológicamente desde una perspectiva biogeográfica (Neme y Gil 2008, 2012). Desde ese marco, la región fue subdividida en tres desiertos (Altoandino, Patagonia y Monte), cada uno de los cuales ha sido ajustado a las provincias fitogeográficas (Neme y Gil 2012). Esta aproximación biogeográfica ha mostrado una escasa cantidad de sitios arqueológicos excavados y analizados en la región de Monte, donde la presencia de campos de cultivo actuales, menor visibilidad y, probablemente, una menor densidad de ocupación, dificultaron la generación de datos arqueológicos (Franchetti 2019).

En los últimos años se iniciaron los análisis de los materiales recuperados en distintos sitios arqueológicos excavados en este sector oriental, cuyos resultados están siendo integrados al debate de las problemáticas regionales (Corbat 2016; Giardina et al. 2015; Llano 2011; Peralta 2019; Pompei 2019; Sugrañes 2017 a). Esta integración permite visibilizar la variabilidad arqueológica presente en la cuenca media del río Atuel (Gil y Neme 2010), que estaba oculta tras la secuencia regional de la Gruta del Indio elaborada por Lagiglia $(1968,2002)$, y que abarcaba desde el Pleistoceno final hasta el Holoceno tardío.

El objetivo del presente trabajo es discutir, a partir del análisis tecnológico, las estrategias de movilidad y modos de ocupación que implementaron las poblaciones humanas en el Atuel medio (sur de Mendoza) durante el Holoceno tardío final (ca. últimos 2000 años AP). Para ello, se aborda el análisis de la tecnología del sitio Los Gallegos 1 (LG-1) y se plantean dos objetivos específicos. El primero consiste en presentar el registro arqueológico de LG-1, localizado en el sector SO de Monte surmendocino. El segundo es evaluar, en el marco específico de la organización tecnológica (sensu Nelson 1991), las tendencias observadas en el estudio de los 
conjuntos líticos y cerámicos del sitio LG-1. Finalmente, se integra esta información junto al registro de sitios cercanos y se evalúan sus tendencias temporales teniendo en cuenta los posibles escenarios demográficos modelados sobre la base de suma de probabilidades de fechas radiocarbónicas.

\section{Contexto Ambiental y Evidencias Arqueológicas de la Cuenca Media del Río Atuel}

El sitio arqueológico LG-1 (Figura 1a) se encuentra al este del valle medio del río Atuel (sur de Mendoza) en la provincia fitogeográfica de Monte (Cabrera 1971). Este es un ambiente árido-semiárido, denominado también como desierto de Monte (Roig 1972), el cual se caracteriza por precipitaciones anuales estivales que varían entre $80 \mathrm{y}$ $250 \mathrm{~mm}$, con un fuerte déficit hídrico anual (Capitanelli 1972; Mares et al. 1985). Los cauces principales de agua con régimen permanente son los ríos Diamante y Atuel, además de algunos arroyos y vertientes en los alrededores del Bloque de San Rafael.

La ocupación humana más antigua del sur de Mendoza proviene de este sector de la cuenca del río Atuel y corresponde al sitio Gruta del Indio, fechado en ca. 11.000 años AP (Neme y Gil 2012). Más allá de estas ocupaciones tempranas, las cuales se continúan de forma intermitente hasta 7000 años $\mathrm{AP}$, se ha propuesto que la ocupación humana efectiva de esta área biogeográfica habría tenido lugar recién hacia los últimos 2000 años AP (Gil y Neme 2010; Neme y Gil 2008). Desde esa fecha, se habría definido a nivel regional un proceso de cambios significativos en las estrategias humanas. Entre ellos, la diversificación del consumo de plantas y especies animales (Corbat 2016; Giardina 2010; Llano 2011; Neme 2007; Neme y Gil 2008), la incorporación de plantas domésticas, el aumento en la circulación de bienes a grandes distancias y la aparición de nuevas tecnologías como la cerámica y el arco y la flecha (Gil 2006; Neme 2007; Pompei 2019; Salgán 2013; Sugrañes 2017a).

Más allá de los cambios mencionados, tal vez el de mayor magnitud tuvo que ver con el establecimiento de grupos con un componente de recursos domesticados en su dieta. La presencia de restos de plantas domésticas, sumada a los resultados de los análisis de isótopos estables, muestra que este sector del desierto de Monte constituyó el límite más austral de la dispersión de la agricultura prehispánica (Gil 1997-1998; Gil et al. 2009, 2011, 2020; Lagiglia 1968, 1999). Sin embargo, el consumo de dichas plantas, especialmente del maíz, nunca habría sido parte importante de la dieta humana prehispánica (Gil et al. 2011, 2014). Su aporte habría sido limitado y, en muchos casos, el acceso a los recursos domésticos pudo haber tenido lugar a través del contacto con productores (Gil 1997-1998, 2006). Recientemente se ha señalado que la importancia cuantitativa de estos recursos en la dieta fue variando entre procesos de incrementos y retracciones en el consumo de las plantas domésticas (Gil et al. 2020). 


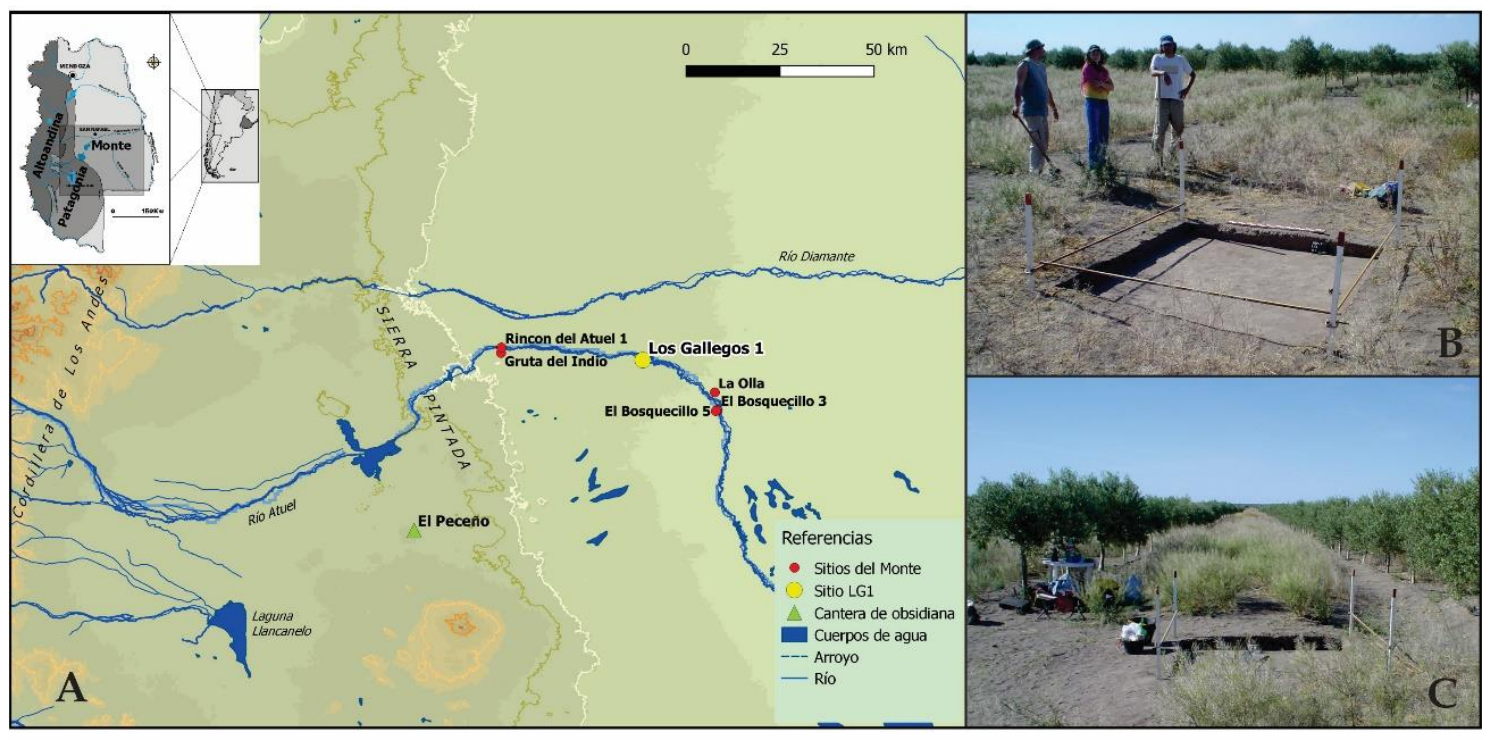

Figura 1. Área de estudio. A) Localización del sitio LG-1 y de los sitios mencionados en el texto; B) Vista de la cuadrícula A1; C) Vista de la cuadrícula B1.

Las evidencias sobre la tecnología lítica en este sector del río Atuel, hacen referencia a una alta diversidad de materias primas explotadas, donde las rocas silíceas y riolitas son mayoritarias (Giardina et al. 2015; Gil et al. 2008). Esto estaría vinculado a la presencia de la Sierra Pintada (Bloque de San Rafael), aguas arriba de la zona de estudio (Figura 1a), en donde este tipo de rocas están disponibles en forma primaria (Abraham 2000; Pompei 2019; Sepúlveda et al. 2000).

La materia prima no local más importante de la región es la obsidiana, cuya fuente más próxima es El Peceño (Cortegoso et al. 2012; Giesso et al. 2011; Salgán y Pompei 2017; entre otros), localizada a unos $80 \mathrm{~km}$ al suroeste de LG-1. Esta fuente presenta evidencias de explotación a partir de la segunda mitad del Holoceno tardío (ca. 1500 años AP) y es la única que se identificó en los sitios arqueológicos de este sector a través del análisis de elementos traza (Pompei 2019; Salgán y Pompei 2017).

En relación a la tecnología cerámica, han sido caracterizados los estilos tecnológicos locales, como Arbolito y Atuel Cepillado, aunque también hay evidencias de estilos perteneciente a la zona Altoandina como Overo/Nihuil (Giardina et al. 2015; Gil 2006; Sugrañes 2019), y de la Zona Central de Chile como Aconcagua (Falabella et al. 2001).

Las cronologías más antiguas del registro cerámico en la provincia de Mendoza, se estiman en, aproximadamente, 2100-2000 años AP (Marsh 2017). En el desierto de Monte, y muy próximo a LG-1, el sitio La Olla (LO) es el que presenta la cerámica más antigua registrada (Figura 1a), con una cronología entre 1700 y 1900 años AP. Aquí fueron identificados tanto los estilos tecnológicos locales de Arbolito y Atuel Cepillado, como de Nihuil, proveniente de los valles intermedios (Giardina et al. 2015; Lagiglia 1977; Sugrañes 2017a). Sugrañes et al. (2020) sostienen que la tecnología cerámica del área muestra un desarrollo local que se mantuvo sin cambios en los últimos 1000 años 
(Sugrañes 2019). Esta tecnología se orientó a contenedores para el traslado y la cocción de alimentos, principalmente con forma de ollas $y$, en menor medida, para almacenamiento (Sugrañes 2017b).

\section{Organización Tecnológica y Movilidad}

Kelly (1983) define la movilidad como la naturaleza de un movimiento estacional de cazadores-recolectores a través de un paisaje, entendiéndola como una propiedad inherente a los individuos. Estos pueden optar por moverse de diferentes maneras: solos o en grupos, frecuentemente o no, por cortas o largas distancias, en escalas diarias, estacionales o anuales (Kelly 1992). Es un fenómeno multidimensional (Kelly 1992) que muchas veces resulta difícil de explicar arqueológicamente (Morgan 2009) y que, además, no deja evidencia material directa (Close 2000). Asimismo, Kuhn (1992) señala que el movimiento está estrechamente relacionado con las fluctuaciones de los recursos comestibles de un área determinada (i.e. Binford 1980), aunque no siempre está directamente controlada por la subsistencia (Kelly 1992). La movilidad tiene una fuerte influencia tanto en la cultura material como en los vínculos sociales, intra e intergrupales (Pallo y Borrero 2015). De esta manera, el registro arqueológico permite rastrear los circuitos y rangos de acción de las poblaciones humanas y la interacción que tuvieron entre ellas en el pasado (Foley 1981; Jones et al. 2003; Kelly 1988, 1992; Kuhn 2004; Meltzer 1989; Renfrew 1977, entre otros).

La tecnología, en este sentido, permitirá resolver ciertos problemas presentados por la estructura energética - entrópica del ambiente en el que procuren subsistir los seres humanos. Las estrategias tecnológicas, además, se complementan con otras, como las de equipamiento, transporte, almacenamiento de recursos y herramientas, interacción social, entre otras (Beck et al. 2002; Eerkens 2012; Hughes 2011; Kelly 1992; Kuhn 2004; Pallo y Borrero 2015, entre otros). Las evidencias tecnológicas muestran las estrategias para hacer, usar, transportar y descartar los utensilios manufacturados y elaborados por un grupo humano (Nelson 1991). En cierta medida, son respuestas del comportamiento de un grupo ante la forma en que se presentan y distribuyen los recursos, y la decisión de cómo explotarlos y moverse dentro de un ambiente; es decir, que dependerán de las elecciones económicas y sociales, así como del equipamiento tecnológico del que disponen.

En el marco de estas ideas se generaron modelos sobre la movilidad de las poblaciones humanas pasadas basadas en el registro arqueológico, particularmente, el tecnológico (Beck 2009; Beck et al. 2002; Bright y Ugan 1999; Eerkens 2003; Jones et al. 2003; Kelly 1983, 1988, 1992; Kuhn 2004; Shott 1986; Simms et al. 1997, entre otros). Estos modelos pueden ser testeados y, si bien no interpelan procesos de complejidad social, permiten (tomando como unidad de análisis al individuo), indagar acerca del comportamiento humano en relación a su medioambiente. El tipo de movilidad implementado constituye una de las estrategias adaptativas utilizadas, y la tecnología responde a esas estrategias (Bamforth 1986; Bettinger et al. 2006; Bettinger y Eerkens 
1999). Desde el análisis de estos modelos, establecimos expectativas arqueológicas para el registro tecnológico lítico y cerámico. Estas expectativas nos permiten evaluar el grado de movilidad residencial de las poblaciones humanas que habitaron el Atuel medio, durante el Holoceno tardío.

\section{Expectativas arqueológicas para la tecnología lítica y cerámica}

La distribución de los artefactos líticos es un indicador de las estrategias y cambios implicados en la movilidad de los grupos humanos (Bamforth 2006; Jones et al. 2003; Kelly 1988; Kuhn 2004; entre otros). Para ello, es necesario considerar la disponibilidad y distribución natural de la materia prima (Andrefsky 1994; Ingbar 1994; Kelly 1992). Por lo tanto, para conocer el territorio por el cual los grupos se movieron, se deben complementar los datos sobre localización y uso de las materias primas presentes en el registro arqueológico con los datos acerca de la producción, uso, mantenimiento y descarte de los instrumentos (Ingbar 1994), y con los factores involucrados en su selección e integración (sensu Nelson 1991) (cf. Bamforth 1986; Kelly 1988; Shott 1986 Torrence 1989; entre otros).

Por otra parte, muchos de los autores que han evaluado las estrategias de movilidad a través del registro lítico, han distinguido entre tipos de movilidad residencial o logística (Binford 1980; Kelly 1988; Kuhn 2004; entre otros), pero no lo han hecho entre grados de movilidad (e.g., movilidad residencial alta o baja). Proponemos la utilización de variables tecnológicas asociadas a las etapas de poblamiento biogeográfico (Franco 2004; Salgán et al. 2012) y al patrón de asentamiento, ya que tales patrones y los de movilidad, están estrechamente vinculados y definen las necesidades artefactuales y el acceso a las materias primas (Carr 1994).

Salgán y colaboradores (2012) aplicaron la propuesta de Franco (2004) al sur de Mendoza, distinguiendo las variaciones esperadas entre un momento de exploración inicial-colonización y otro de ocupación efectiva. Estos autores señalan que la calidad de las materias primas locales mejoraría con el tiempo, desde rocas de baja calidad a muy buena -o mejor a las disponibles. Por su parte, la calidad de las rocas exóticas sería excelente tanto en un escenario como en otro (Salgán et al. 2012). Asimismo, la frecuencia de materias primas no locales aumentaría en detrimento de las rocas locales (Salgán et al. 2012). En este punto debemos considerar que, ante una alta movilidad residencial se espera que los grupos tengan mayor posibilidad de seleccionar y aprovisionarse -de forma directa- de las rocas de mejor calidad debido a la amplitud de los rangos de acción. Por otro lado, aquellos grupos con baja movilidad residencial y rangos de acción más acotados, tendrán acceso, principalmente, a las rocas disponibles en lo inmediato. El acceso a materias primas de excelente calidad de procedencia no local, se realizará a través de la interacción con otros grupos (Pallo y Borrero 2015; entre otros) o de forma directa por medio de incursiones a la fuente de aprovisionamiento por una parte del grupo (e.g. Gil 2000). 
La disminución en la movilidad residencial generaría estadías más largas en un mismo locus, lo que se refleja en: una mayor diversidad de clases artefactuales, producto de múltiples actividades y/o equipando el sitio (Kuhn 2004; Shott 1986); mayor frecuencia de desechos de talla (Hitchcock 1987) e instrumentos en roca local (Carr 1994) y no local (Salgán et al. 2012) y, por lo tanto, mayor índice de producción (sensu Ericson 1984); mayores índices de fractura de artefactos por pisoteo y/o por descarte en el lugar (Franco 2004); y, por último, secuencia de reducción completa en el sitio, reflejada por la representación de todas las etapas de manufactura (Hitchcock 1987; Nelson 1991), la disminución en el tamaño de los artefactos (Franco 2004) debido al aumento en el mantenimiento y/o la reactivación de filos, y por núcleos menos frecuentes y agotados (Salgán et al. 2012).

Desde el registro cerámico, distintos autores tomaron en consideración diversos aspectos tecnológicos de las vasijas cerámicas, acentuando determinados conceptos, como la inversión de trabajo (Simms et al. 1997), el tipo de movilidad (Eerkens 2003), la reocupación de sitios (Bright y Ugan 1999) o las relaciones de grupos móviles con agricultores (Beck 2009). Si bien no hay una asociación directa entre determinado atributo y una alta o baja movilidad, la elección de determinadas características en la manufactura cerámica, de manera integral, nos permite establecer las estrategias y organización de grupos móviles.

Para que un grupo humano se involucre con la tecnología cerámica son necesarios tres aspectos: arcilla y agua disponible, un clima favorable y una estancia mínima en un lugar para el proceso de levantado, secado y cocción de la vasija (Arnold 1985). Los ejemplos de grupos móviles con tecnología cerámica son escasos dados los conflictos que acarrea su manufactura y una vida móvil (Eerkens 2003). Sin embargo, hay grupos que resolvieron esos conflictos, como en el caso del sur de Mendoza (Lagiglia 1997; Sugrañes 2017a).

Para Simms et al. (1997) un espesor fino significa una alta inversión de trabajo y tiempo de manufactura, por lo que estaría vinculado a grupos con baja movilidad. Por el contrario, Eerkens (2003) considera que los grupos móviles buscarían afinar las paredes por dos motivos, para obtener vasijas más livianas, o para mejorar la conductividad del calor. En nuestro caso, consideramos que para el sur de Mendoza, un espesor fino, menor a $4 \mathrm{~mm}$, estará asociado a: una mayor inversión en la manufactura cerámica (preparado de la arcilla, afinamiento de las paredes), para lo cual es necesario una mayor permanencia en el lugar; y/o vinculado al acceso de vasijas a partir de la interacción entre grupos humanos. En este sentido, el criterio de abundancia postulado por Bishop et al. (1982) estará ligado a estos procesos.

En grupos altamente móviles se espera una baja inversión en el tratamiento de superficie (Eerkens 2003), con vasijas preferentemente alisadas (en lugar de las pulidas), lo que mejora su efectividad calórica. Por el contrario, las vasijas con superficies pulidas mejoran la impermeabilización y están asociadas a funciones como el almacenamiento, aspectos que no estarían vinculados a una alta movilidad (Simms et al. 1997). 
Eerkens (2003) sostiene que vasijas de tamaño pequeño y liviano son acordes a una alta movilidad, y éstas estarán, principalmente, orientadas a la cocción y recolección de recursos comestibles, por lo que es esperable, además, una baja proporción de vasijas decoradas. Brigth y Ugan (1999), por otro lado, consideran que se observará una baja variabilidad morfológica cuando la movilidad humana es alta, dado que estos grupos necesitan una tecnología confiable, y no tenderán a experimentar con la misma (Eerkens 2003). En este sentido, esperamos una baja diversidad tecnológica y tipológica.

Asimismo, ante una alta movilidad se espera que la manufactura se realice en distintos espacios, lo que evidenciará una diversidad química alta producto del uso de distintas arcillas (Eerkens 2003). Finalmente, ante una baja movilidad y producto de un aumento de las redes de interacción, consideramos que se observará un aumento en la presencia de estilos no locales.

Siguiendo estas premisas, en la Tabla 1 presentamos una serie de expectativas tanto para el conjunto lítico como para el cerámico del sitio LG-1 de acuerdo al tipo de movilidad residencial. Advertimos que las expectativas que planteamos no son dicotómicas, por lo que una misma evidencia no necesariamente tiene que ver con un solo tipo de estrategia de movilidad, pero que, analizadas en conjunto, nos proveen de una respuesta más fiable.

\section{Metodología}

El análisis de los conjuntos líticos y cerámicos del sitio LG-1 se llevó a cabo desde un enfoque tecno-tipológico clásico de ambos registros (Aschero 1975, 1983; Orton et al. 1993). El examen del conjunto lítico incluye las piezas enteras y las fracturadas, aunque para el estudio de las variables de reserva de corteza, dimensiones de los artefactos y etapas de manufactura (iniciales o de descortezamiento, intermedias y finales) de los desechos de talla, solo se tomaron las piezas enteras. El registro cerámico, en cambio, corresponde en su totalidad a fragmentos, aunque se cuenta con un registro de referencia de vasijas enteras pertenecientes a museos de la región (Sugrañes 2017b).

\section{Conjunto lítico}

Las materias primas se determinaron por petrografía macroscópica y por su calidad para la talla (sensu Aragón y Franco 1997). La reserva de corteza se consideró según el porcentaje de cobertura en cada pieza (sensu Aschero 1975, 1983; Franco 2002). Se midieron largo, ancho y espesor de todos los artefactos. En los enteros, esta variable permitió evaluar la estadística descriptiva y estimar el volumen de las piezas. Además, se determinó la superficie artefactual de cada desecho utilizando una grilla milimetrada en intervalos de 5 mm (sensu Franco 2002). Así, los desechos de tamaño igual o menor a $5 \mathrm{~mm}$ de lado, designados como "microdesechos" (sensu Sherwood 2001) fueron contabilizados, pero excluidos del análisis tecnológico debido a que muchos de los atributos requeridos para la definición del tipo de desecho no son discernibles con precisión a ese tamaño. 


\begin{tabular}{|c|c|c|c|}
\hline Tecnología & Variables & Alta movilidad residencial & Baja movilidad residencial \\
\hline \multirow{10}{*}{$\underset{\Xi}{U}$} & $\begin{array}{c}\text { Calidad Mat. } \\
\text { Primas }\end{array}$ & Buena & Muy buena \\
\hline & $\begin{array}{l}\text { Diversidad de } \\
\text { clases }\end{array}$ & Baja & Alta \\
\hline & $\begin{array}{l}\text { Estado de los } \\
\text { conjuntos }\end{array}$ & Poca fragmentación & Mayor fragmentación \\
\hline & $\begin{array}{c}\text { Etapa de } \\
\text { manufactura }\end{array}$ & Intermedias y finales & Todas \\
\hline & $\begin{array}{l}\text { Frecuencia de } \\
\text { núcleos }\end{array}$ & Alta & Baja \\
\hline & $\begin{array}{c}\text { MP local/No } \\
\text { local }\end{array}$ & Muy alta/Baja & Media-Alta/Media-Baja \\
\hline & $\begin{array}{c}\text { Frecuencia de } \\
\text { desechos de } \\
\text { talla }\end{array}$ & Alta & Muy alta \\
\hline & $\begin{array}{l}\text { Frecuencia de } \\
\text { instrumentos }\end{array}$ & Baja & Media-Alta \\
\hline & $\begin{array}{c}\text { Índice de } \\
\text { Producción }\end{array}$ & Bajo & Alto \\
\hline & Tamaño artef. & Mediano-Pequeño & Pequeño-Muy pequeño \\
\hline \multirow{10}{*}{ 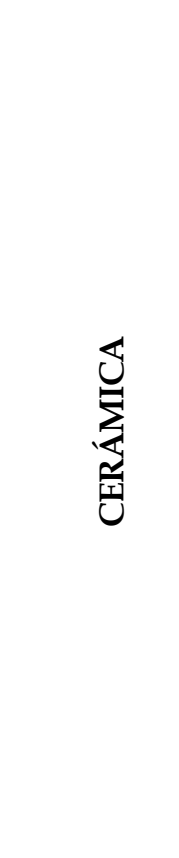 } & Espesores & Medios(ca.>4mm)/Gruesos & Finos $(c a .<4 \mathrm{~mm}) / \operatorname{Medios}(c a .>4 \mathrm{~mm})$ \\
\hline & $\begin{array}{l}\text { Tratamiento } \\
\text { Superficie }\end{array}$ & Alisado & Alisado y Pulido \\
\hline & $\begin{array}{c}\text { Frecuencia de } \\
\text { decoración }\end{array}$ & Baja & Alta \\
\hline & $\begin{array}{c}\text { Tamaño } \\
\text { contenedores }\end{array}$ & Pequeño/Mediano & Mediano/Grande \\
\hline & $\begin{array}{c}\text { Variedad de } \\
\text { formas }\end{array}$ & Baja & Alta \\
\hline & $\begin{array}{l}\text { Frecuencia de } \\
\text { estilos locales }\end{array}$ & Alta & Alta \\
\hline & $\begin{array}{c}\text { Frecuencia est. } \\
\text { no locales }\end{array}$ & Baja & Alta \\
\hline & $\begin{array}{c}\text { Div. } \\
\text { tecnológica }\end{array}$ & Baja & Alta \\
\hline & Div. química & Alta & Baja \\
\hline & Div. tipológica & Baja & Alta \\
\hline
\end{tabular}

Tabla 1. Expectativas arqueológicas sobre movilidad para el registro lítico y cerámico de LG-1. Referencias: MP: materia prima; Índice de producción: desechos de talla/instrumentos. 


\section{Conjunto cerámico}

Los fragmentos cerámicos fueron limpiados y sometidos a análisis macroscópicos y con lupa binocular, a partir de un corte en fresco para observar la pasta. Las variables relevadas y analizadas en este trabajo son el tratamiento de superficie y medidas del fragmento (largo, ancho y espesor) (Orton et al. 1993; Rye 1988). Además, se consideraron las huellas de uso como presencia de hollín y residuos orgánicos y, también, rasgos postdepositacionales como sales, raíces y alteraciones del fragmento. Se identificaron estilos tecnológicos. También, se realizaron análisis de activación neutrónica a diez fragmentos del sitio en el Laboratorio de Arqueometría de la Universidad de Missouri, siguiendo los protocolos establecidos en dicha institución (Glascock 1992). Los resultados fueron procesados en esta Universidad y se utilizó el programa GAUSS para los gráficos.

\section{Los Gallegos 1}

El sitio LG-1 fue detectado a partir del estudio de impacto realizado previamente a la construcción de la obra "Canal Marginal del Atuel" durante el año 2004. Es un sitio a cielo abierto que se encuentra ubicado sobre el último tramo de la cuenca media del río Atuel (Figura 1a), sobre su margen derecha y a unos 600 metros lineales de la barranca del mismo. Emplazado en las márgenes de la terraza del río, su altura sobre el nivel del mar es de $577 \mathrm{~m}$ y sus coordenadas geográficas son $34^{\circ} 47^{\prime} 43,31^{\prime \prime} \mathrm{LS}$ y $67^{\circ} 57^{\prime} 8,15^{\prime \prime} \mathrm{LO}$. El mismo se encuentra en un área actualmente cultivada con olivos, en la localidad de Villa Atuel.

La superficie del sitio es de $2160 \mathrm{~m}^{2}$, sobre ella se decidió plantear dos cuadrículas de $2 \times 2 \mathrm{~m}$ en sentido norte-sur en los sectores con mayor densidad de hallazgos superficiales. La cuadrícula A1 (Figura 1b) se encuentra a $628 \mathrm{~m}$ de distancia de las barrancas del río Atuel y la cuadrícula B1 (Figura 1c) se localiza cerca del límite actual de la plantación de olivos (a 20 metros de A1), la cual reemplazó a otras plantaciones previas de viñedos de principios del siglo XX. Es por esto, que asumimos que el sitio fue modificado por las labores agrícolas que llevan décadas en el lugar (Ots 2008).

\section{Estratigrafía y Cronología}

Ambas cuadrículas se dividieron en cuatro sectores de excavación según la orientación (NE, NO, SE y SO) y se trabajó por niveles artificiales de $5 \mathrm{~cm} \mathrm{y} 10 \mathrm{~cm}$, según la cantidad de material arqueológico registrado en cada nivel. En la cuadrícula A1 se llegó hasta el nivel 10 y se alcanzó una potencia total de $72 \mathrm{~cm}$. Por su parte, en la cuadrícula B1 se excavó hasta el nivel 11, alcanzando los $86 \mathrm{~cm}$ de profundidad. Si bien la cuadrícula A1 se estableció por fuera del área de cultivo (Figura 1b) y la cuadrícula B1, sobre los callejones que separan las hileras de los olivares (Figura 1c), toda el área muestra indicios de estar retrabajada por el uso del arado, por lo que se asumió que al menos los primeros $30 \mathrm{~cm}$ de las dos cuadrículas estarían modificados. 
La estratigrafía de ambas cuadrículas se define por dos unidades sedimentarias A y B (Figura 2). La unidad sedimentaria A se diferenció en A 1 y A 2, dado que se presenta con características diferentes entre los primeros centímetros y los de mayor profundidad (Figura 2). El sector A 1 se compone de arena friable con motas de ceniza volcánica. La parte denominada A 2, comienza a los $50 \mathrm{~cm}$ de la excavación donde la arena contiene pumicita y raíces entremezcladas en el sedimento arenoso. Sobre el sector suroeste de esta cuadrícula, se observó una especie de estructura con mayor cantidad de ceniza y bordes de materia orgánica. A los $70 \mathrm{~cm}$ de profundidad, la arena se tornó más compacta mezclada con áreas limo arcillosas, hasta alcanzar la unidad sedimentaria B. Los materiales arqueológicos se recuperaron en la unidad sedimentaria A.

Se realizaron dos fechados radiocarbónicos sobre carbón disperso en capa proveniente de la cuadrícula B1 (Tabla 2 y Figura 2). Si bien los fechados se encuentran invertidos en cuanto a la profundidad, las diferencias no son estadísticamente significativas $\left(t=1,9 ; X^{2}=3,84\right)$, por lo que se considera que el sitio LG-1 tiene una cronología de $1217 \pm 37$ años ${ }^{14} \mathrm{C}$ AP (mediana calibrada 1082 años cal. AP).

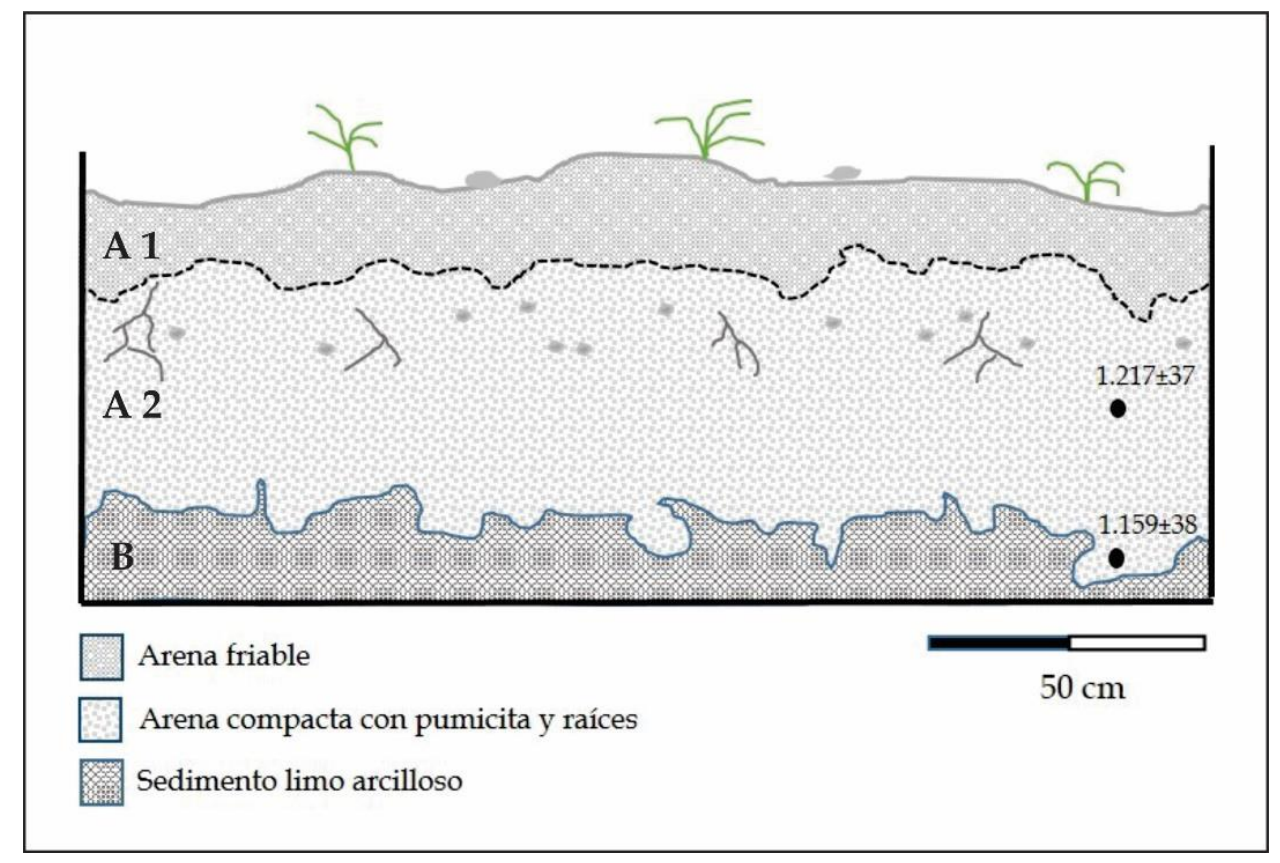

Figura 2. Esquema general del perfil de la cuadrícula B1 del sitio LG-1.

\begin{tabular}{|c|c|l|c|c|c|}
\hline Cuadrícula & Nivel & Código & Años ${ }^{14}$ C AP & $\begin{array}{l}\text { Años cal. AP } \\
\text { (mediana) }\end{array}$ & Material \\
\hline B1 & 6 & AA-66580 & $1217 \pm 37$ & 1082 & Carbón \\
\hline B1 & 10 & AA-66581 & $1159 \pm 38$ & 1014 & Carbón \\
\hline
\end{tabular}

Tabla 2. Fechados radiocarbónicos y edades calibradas en LG-1. La calibración se realizó con el programa CALIB 7.1.0 (Stuiver et al. 2020), y se usó la curva atmosférica SHCal13 para el hemisferio sur (Hogg et al. 2013). 


\section{El Registro Arqueológico de LG-1}

Las dos cuadrículas excavadas en el sitio LG-1 poseen una composición semejante en cuanto a restos arqueológicos, aunque en la cuadrícula A1 no se recuperaron fragmentos cerámicos (Tabla 3) (Sugrañes 2017a). Sin embargo, aquí los análisis son tratados en conjunto. Esta decisión metodológica se basa, principalmente, en esa similitud del registro y de la estratigrafía, además de la estrecha cercanía entre ambas cuadrículas. En la cuadrícula A1 se recuperaron 260 elementos, mientras que en la cuadrícula B1, 984 (Tabla 3). Estos se recuperaron en la unidad sedimentológica A (Figura 2); sin embargo, los elementos recuperados en la cuadrícula A1 muestran una mayor densidad en los primeros cuatro niveles (primeros $30 \mathrm{~cm}$ ), mientras que en la B1, esta mayor densidad se encuentra entre los niveles 6 y 9 (entre los 40 y $65 \mathrm{~cm}$ ) (Tabla 3). Las unidades sedimentarias de ambas cuadrículas muestran similitud en su conformación geomorfológica (Figura 2). Por lo que, consideramos que esta presencia diferencial del registro puede deberse a la localización de las cuadrículas vinculadas al uso actual de espacio. Es decir, que la cuadrícula B1 puede haber sido más afectada en los primeros centímetros por el uso del arado, que la cuadrícula A1 (Ots 2008).

Los elementos arqueofaunísticos se hallan en un estado avanzado de meteorización (3-5), y muy fragmentados, lo que resultó en la obtención de 947 astillas (Tabla 3), sin identificación taxonómica, con excepción de los fragmentos de cáscaras de huevo de Rehidae en ambas cuadrículas (A1: $\mathrm{N}=28$; $\mathrm{B} 1$ : $\mathrm{N}=166$ ).

\begin{tabular}{|c|c|c|c|c|c|}
\hline \multirow{2}{*}{ Nivel } & \multicolumn{2}{|c|}{ Cuadrícula A1 } & \multicolumn{3}{c|}{ Cuadrícula B1 } \\
\cline { 2 - 6 } & Óseo & Lítico & Óseo & Lítico & Cerámica \\
\hline $\mathbf{1}$ & $77(53,5 \%)$ & $44(37,9 \%)$ & $55(6,8 \%)$ & $21(13,1 \%)$ & - \\
\hline $\mathbf{2}$ & $36(25 \%)$ & $36(31 \%)$ & $51(6,4 \%)$ & $16(10 \%)$ & - \\
\hline $\mathbf{3}$ & $29(20,1 \%)$ & $16(13,8 \%)$ & $50(6,2 \%)$ & $4(2,6 \%)$ & - \\
\hline $\mathbf{4}$ & $2(1,4 \%)$ & $5(4,3 \%)$ & $21(2,7 \%)$ & $18(11,2 \%)$ & $2(9,5 \%)$ \\
\hline $\mathbf{5}$ & - & $4(3,5 \%)$ & $68(8,5 \%)$ & $10(6,2 \%)$ & $2(9,5 \%)$ \\
\hline $\mathbf{6}$ & - & - & $216(26,9 \%)$ & $17(10,7 \%)$ & $3(14,4 \%)$ \\
\hline $\mathbf{7}$ & - & $2(1,7 \%)$ & $149(18,5 \%)$ & $21(13,1 \%)$ & $4(19 \%)$ \\
\hline $\mathbf{8}$ & - & - & $76(9,5 \%)$ & $9(5,6 \%)$ & $1(4,7 \%)$ \\
\hline $\mathbf{9}$ & - & - & $67(8,3 \%)$ & $31(19,4 \%)$ & $2(9,5 \%)$ \\
\hline $\mathbf{1 0 a}$ & - & $9(7,8 \%)$ & $48(6 \%)$ & $12(7,5 \%)$ & $7(33,4 \%)$ \\
\hline $\mathbf{1 0 b}$ & & & $1(0,1 \%)$ & $1(0,6 \%)$ & - \\
\hline $\mathbf{1 1}$ & & & $1(0,1 \%)$ & - & - \\
\hline Total & $\mathbf{1 4 4}$ & $\mathbf{1 1 6}$ & $\mathbf{8 0 3}$ & $\mathbf{1 6 0}$ & $\mathbf{2 1}$ \\
\hline
\end{tabular}

Tabla 3. Materiales arqueológicos recuperados de las cuadrículas A1 y B1 del sitio LG-1 por nivel artificial de excavación. Las celdas en gris señalan ausencia de excavación. 
Registro lítico

De la cuadrícula A1, se recuperaron 116 artefactos líticos (Tabla 3), de los cuales fueron analizados 50 (43\%); de B1, se recuperaron 160 y se consideraron 64 (40\%; no se analizaron los microdesechos; véase Metodología). Por lo tanto, se analizó un total de 114 artefactos líticos (Tabla 4). La mayor parte de la muestra lítica de LG-1 está representada por desechos de talla $(96 \%, \mathrm{~N}=109)$ y se registraron cinco nódulos (4\%). Se distinguieron siete materias primas líticas, siendo las tres principales las silíceas, la riolita y el basalto (Tabla 4). Todas las clases de roca se registraron entre los desechos de talla. En el caso de los nódulos, tres son de cuarzo, uno de basalto y otro de riolita.

La totalidad de las rocas utilizadas, salvo la obsidiana, son locales. Las limitaciones en el tamaño y espesor de los artefactos de obsidiana no posibilitaron la aplicación de la técnica no destructiva de Fluorescencia de Rayos-X (XRF), pero es probable que esta roca provenga de la fuente El Peceño (Salgán y Pompei 2017), la única recuperada en los sitios cercanos a LG-1 (Pompei 2019).

\begin{tabular}{|c|c|c|c|c|c|c|c|}
\hline Materias & Frec. & \multicolumn{4}{|c|}{ Calidad } & \multicolumn{3}{c|}{ Estado } \\
\cline { 3 - 8 } primas & MP & EX & MB & B & Entero & Fracturado & ND \\
\hline Andesita & $1 \%(1)$ & - & - & $100 \%(1)$ & - & $100 \%(1)$ & - \\
\hline Basalto & $9 \%(10)$ & - & $10 \%(1)$ & $90 \%(9)$ & - & $90 \%(9)$ & $10 \%(1)$ \\
\hline Cuarzo & $5 \%(6)$ & - & $33 \%(2)$ & $67 \%(4)$ & $17 \%(1)$ & $50 \%(3)$ & $33 \%(2)$ \\
\hline Obsidiana & $3 \%(3)$ & $100 \%(3)$ & - & - & - & $100 \%(3)$ & - \\
\hline Riolita & $29 \%(33)$ & - & $30 \%(10)$ & $70 \%(23)$ & $6 \%(2)$ & $88 \%(29)$ & $6 \%(2)$ \\
\hline Silíceas & $52 \%(59)$ & - & $75 \%(44)$ & $25 \%(15)$ & $10 \%(6)$ & $88 \%(52)$ & $2 \%(1)$ \\
\hline Indet. & $2 \%(2)$ & - & - & $100 \%(2)$ & - & $100 \%(2)$ & - \\
\hline Total (n) & $\mathbf{1 1 4}$ & $\mathbf{3}$ & $\mathbf{5 7}$ & $\mathbf{5 4}$ & $\mathbf{9}$ & $\mathbf{9 9}$ & $\mathbf{6}$ \\
\hline Total (\%) & $\mathbf{1 0 0}$ & $\mathbf{3}$ & $\mathbf{5 0}$ & $\mathbf{4 7}$ & $\mathbf{8}$ & $\mathbf{8 7}$ & $\mathbf{5}$ \\
\hline
\end{tabular}

Tabla 4. Frecuencia de materias primas, calidad para la talla y estado de fragmentación de los artefactos líticos de LG-1. Referencias: MP: materias primas; EX: excelente; MB: muy buena; B: buena. Fract.: fracturado; ND: no diferenciado.

Se observa un predominio de la calidad de materia prima "muy buena" (mayormente representada en rocas silíceas) por sobre la "buena" (principalmente en riolita y basalto). La calidad "excelente" está presente solo sobre obsidiana (Tabla 4). El $87 \%$ de los artefactos se encuentra fracturado, el $8 \%$ está entero y el $5 \%$ restante corresponde a artefactos en los que no se pudo diferenciar esta variable. La mayor frecuencia de artefactos enteros se da principalmente sobre rocas silíceas (Tabla 4).

El $67 \%$ de los artefactos líticos enteros no posee reserva de corteza (83\% en rocas silíceas y $17 \%$ en riolita; tipológicamente corresponden a seis lascas angulares), mientras que el $33 \%$ restante lo constituye una lasca angular de roca silícea con $50 \%$ de corteza, y dos nódulos, uno de cuarzo con 50 \% de corteza y otro de riolita cubierto 
$100 \%$ de corteza. Por otra parte, las medidas de largo y ancho de los desechos de talla promedian valores inferiores a los $1,5 \mathrm{~cm}$; es decir, poseen dimensiones pequeñas (Tabla 5). La ausencia de núcleos e instrumentos no nos permite deducir fehacientemente qué tamaños tuvieron las formas-base seleccionadas; aunque sabemos que las dimensiones de los dos nódulos enteros no alcanzan los $3 \mathrm{~cm}$ (Largo máx. $=27$ $\mathrm{mm}$; Ancho máx.= $23 \mathrm{~mm}$ ). Por lo tanto, podemos proponer que las formas-base que ingresaron a LG-1 también eran de pequeñas dimensiones.

\begin{tabular}{|c|c|c|c|c|c|}
\hline \multicolumn{6}{|c|}{ Dimensiones de los desechos de talla enteros } \\
\hline MP & $\begin{array}{l}\text { Largo } \\
\text { (mm) }\end{array}$ & $\begin{array}{c}\text { Ancho } \\
\text { (mm) }\end{array}$ & $N$ & 7 & 7 \\
\hline Riolita & 8,00 & 14,00 & Media & 12,4 & 11,1 \\
\hline Silíceas & 10,0 & 15,0 & $\begin{array}{c}\text { Desv. } \\
\text { Estándar }\end{array}$ & 4,8 & 4,7 \\
\hline Silíceas & 10,5 & 7,0 & Mínimo & 8,0 & 5,5 \\
\hline Silíceas & 17,0 & 16,0 & Máximo & 21,0 & 16,0 \\
\hline Silíceas & 11,5 & 5,5 & Rango & 13,0 & 10,5 \\
\hline Silíceas & 21,0 & 14,0 & & & \\
\hline Silíceas & 9,0 & 6,0 & & & \\
\hline
\end{tabular}

Tabla 5. Estadística descriptiva de las características métricas (en milímetros) de los desechos de talla enteros de LG-1.

Se pudieron distinguir lascas internas, todas angulares $(N=7)$. Las etapas iniciales o de descortezamiento, y las etapas finales de manufactura y/o de reactivación de filos, no fueron registradas en LG-1.

En suma, la baja proporción de corteza, la presencia únicamente de lascas angulares, el tamaño pequeño de los artefactos y la ausencia de núcleos e instrumentos, señalan que las etapas iniciales y finales de la manufactura se realizaron en otros lugares, y que en el sitio LG-1 se llevaron a cabo solamente las etapas intermedias de formatización de formas-base y/o actividades vinculadas al mantenimiento de instrumentos; estos últimos utilizados y descartados en otros loci.

Registro cerámico

Se recuperó un total de 21 fragmentos cerámicos, todos en la cuadrícula B1 (Tabla 3). Además, se recolectaron otros seis fragmentos en superficie. Esta baja cantidad de fragmentos cerámicos es esperable en sitios de cazadores-recolectores (Eerkens 2003). No hay variaciones importantes en la cantidad de fragmentos a lo largo de la secuencia de excavación, con la salvedad de que comienzan en el nivel 4 (Tabla 3). La alteración en la asociación estratigráfica y en la distribución de los fragmentos puede estar vinculada al trabajo de arado y pisoteo (Ots 2008). 
El estado de preservación de los materiales es bueno, con altos porcentajes de huellas postdepositacionales en ambas superficies como sales y marcas de raíces y, en menor medida, afectadas por el quebramiento, laminado y saltado del tratamiento superficial (Rye 1988). El tamaño de los fragmentos es mayoritariamente pequeño $(<10$ $\left.\mathrm{cm}^{2}\right)$ (89\%), con una fractura regular que podría asociarse a los procesos postdepositacionales generados por el trabajo de labranza (Orton et al. 1993; Ots 2008; Rye 1988).

Se determinó un número mínimo de cuatro vasijas (Feely y Ratto 2013). A partir de fragmentos diagnósticos (dos bordes y dos cuellos) se pudieron inferir formas que corresponden a ollas restringidas, de acuerdo a relevamientos de vasijas enteras de la región (Lagiglia 1997; Sugrañes 2017b). Las mismas serían ollas cerradas con perfil complejo (Shepard 1985 [1956]), de bases redondeadas y de un tamaño mediano a pequeño, de aproximadamente unos $20 \mathrm{~cm}$ de alto y con bocas no mayores a $15 \mathrm{~cm}$. Estas ollas se habrían utilizado para cocción de alimentos dada la presencia de huellas de uso como residuos orgánicos, hollín y rastros de atrición sobre las superficies de algunos fragmentos, principalmente en el lado interno.

En el tratamiento de superficie predomina el alisado (70 \%) con mínima presencia de cepillado (7\%) y pulido (15\%), estos dos últimos en la superficie externa; el resto (8 $\%)$ se encuentra afectado en sus superficies por lo que no se pudo determinar su tratamiento. El único fragmento decorado es un inciso de líneas paralelas gruesas. El espesor del conjunto ronda entre los 5,3 mm con muy baja variabilidad (mín. 4,2 mm y máx. 6,8 mm; desvío estándar=0,10). La cocción de las vasijas es, principalmente, oxidante $(89 \%)$, con presencia de algunos fragmentos con cocción reductora $(7,4 \%)$, posiblemente, producto de cocciones a cielo abierto y a baja temperatura (Rye 1988). Además, las pastas se desgranan fácilmente, lo que puede ser resultado de lo anteriormente mencionado.

El 55,5 \% de los fragmentos se asociaron a algún estilo tecnológico conocido (sensu Sugrañes y Franchetti 2012; Sugrañes 2017 b, 2019): Arbolito/Atuel (47 \%) y Atuel Cepillado $(7 \%)$ corresponden a los estilos considerados locales al área de estudio, mientras que Nihuil/Overo (26 \%) y Marrón Pulido (20 \%) a estilos no locales. En el primer caso, proviene del sector cordillerano (Altoandino; Figura 1a) del sur de Mendoza, mientras que el segundo, de la actual Zona de Chile Central (Falabella et al. 2001; Lagiglia 1997; Sugrañes 2019).

Se realizaron análisis de activación neutrónica en 10 muestras cerámicas del sitio (Sugrañes 2019; Sugrañes et al. 2020). Los resultados del conjunto analizado en LG-1 se distribuyen en dos grupos químicos: el 90 \% corresponde al agrupamiento químico G5 y el 10 \% restante pertenece al grupo G3 (Figura 3a) (Sugrañes et al 2020). Sugrañes et al. (2020) sostienen que G5 responde a producciones locales de la cuenca del río Atuel, específicamente, al Monte. A partir de los estilos tecnológicos que agrupa este conjunto, se sostiene la hipótesis de una producción local en 
relación al área de estudio. El fragmento asignado a G3 (Sugrañes et al. 2020) está asociado a la zona cordillerana. El mismo fue adscripto al estilo tecnológico de Nihuil/Overo y es considerado como proveniente de una vasija de producción no local al sitio. Lo que diferencia a G3 y G5 es la proporción de Fe, La y Ce. El G3 es el que contiene mayor cantidad de Fe con respecto al G5 (Figura 3b); mientras que este último posee mayor presencia de La y Ce.

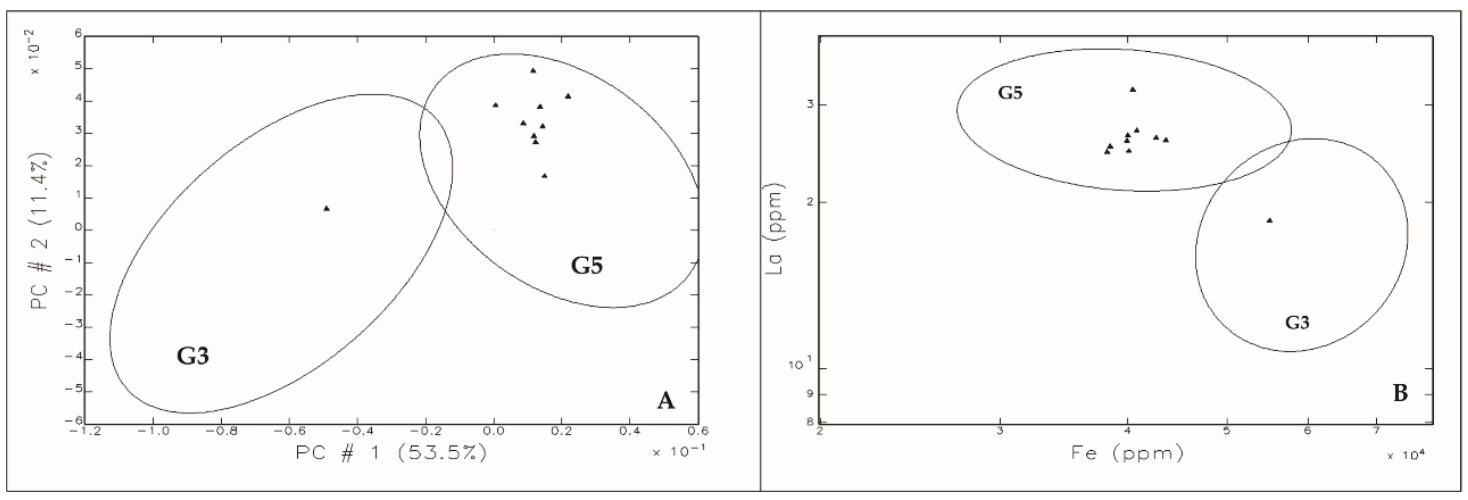

Figura 3. Análisis de componentes principales. a) Distribución de los CP1 y CP2 de la muestra analizada en el sitio LG-1, por grupo composicional discreto; b) Detalle de la dispersión de los fragmentos del G3 y G5 con sus elipses de los elementos Fe vs. La. Las elipses de confianza muestran el grado de dispersión de las muestras con respecto a su centro (95 \%).

\section{Funcionalidad de LG-1 en el contexto regional}

LG-1 presenta evidencias de ocupación humana durante el Holoceno tardío final, a partir de $1217 \pm 37$ años ${ }^{14} \mathrm{C}$ AP (mediana calibrada 1082 años cal. AP). La presencia de alteraciones postdepositacionales, se puede haber generado por actividades agrícolas contemporáneas y/o migración vertical, entre otras (Ots 2008). La distribución de los distintos tipos de materiales nos permite considerar al sitio como un solo conjunto correspondiente a un único evento de ocupación, o un promedio de eventos próximos en el tiempo.

Las tendencias de las líneas de evidencia consideradas muestran al sitio como un campamento donde se realizaron múltiples actividades, entre las que se incluyen el procesamiento y consumo de alimentos, y la confección y/o mantenimiento de instrumentos. Esto se infiere por la presencia de fragmentos de vasijas con evidencias de cocción y desechos de talla con atributos asignados a etapas intermedias de formatización y/o mantenimiento de instrumentos. Más allá de que el material zooarqueológico no pudo determinarse, es altamente probable que los restos recuperados estén asociados a actividades de consumo en el sitio. Además, la proximidad de LG-1 al cauce del río Atuel señala que se habría priorizado la cercanía a este recurso crítico en el desierto de Monte (Figura 1 a). 
La Tabla 6 señala los resultados obtenidos del análisis de las variables que hemos propuesto para definir el tipo de movilidad residencial (Tabla 1). LG-1 muestra un uso casi exclusivo de materias primas locales. Las características tecno-tipológicas de los fragmentos cerámicos corresponden, también, a un conjunto local en la cuenca media del río Atuel. La forma de las ollas y los residuos orgánicos adheridos a los fragmentos muestran utensilios cerámicos orientados a la cocción de alimentos.

\begin{tabular}{|c|c|c|}
\hline Tecnología & Variables & LG-1 \\
\hline \multirow{10}{*}{ : } & Calidad Materias Primas & Muy buena $(57 \%)$ \\
\hline & Diversidad de clases artefactuales & Baja (Simpson=0,08) \\
\hline & Estado de los conjuntos líticos & Alta fragmentación $(87 \%)$ \\
\hline & Etapa de manufactura & Intermedias (100\%) \\
\hline & Frecuencia de núcleos & Ausentes \\
\hline & Frecuencia MP local/No local & Muy alta (97 \%)/Baja (3 \%) \\
\hline & Frecuencia de desechos de talla & Muy alta $(96 \%)$ \\
\hline & Frecuencia de instrumentos & Ausentes \\
\hline & Índice de Producción & Nula (0) \\
\hline & Tamaño de los artefactos & $\begin{array}{c}\text { Pequeño (57 \%)-Muy } \\
\text { pequeño }(43 \%)\end{array}$ \\
\hline \multirow{10}{*}{ 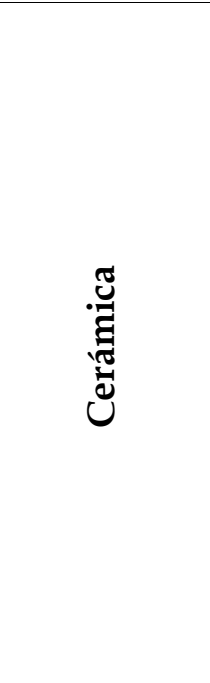 } & Medida espesores & $\begin{array}{c}\text { Finos }(4,2 \mathrm{~mm}) / \text { Medios } \\
\text { (6,8 mm })\end{array}$ \\
\hline & Tratamiento de superficies & $\begin{array}{c}\text { Alisados (70 \%)- Pulidos } \\
\text { (14\%) }\end{array}$ \\
\hline & Frecuencia de decoración & Baja $(\mathrm{N}=1)$ \\
\hline & Tamaño de contenedores & Pequeño \\
\hline & Variedad de formas & Alta $(\mathrm{N}=4)$ \\
\hline & Frec. de Estilos cerámicos locales & Alta $(80 \%)$ \\
\hline & Frec. de Estilos cerámicos no locales & Baja $(20 \%)$ \\
\hline & Diversidad tecnológica & Alta (Simpson=0,69) \\
\hline & Diversidad química & Baja (2 G) \\
\hline & Diversidad tipológica & Alta (Simpson=0,69) \\
\hline
\end{tabular}

Tabla 6. Variables evaluadas para conocer el tipo de movilidad (Tabla 1) y resultados obtenidos del análisis tecnológico de LG-1.

La presencia mínima de obsidiana sugiere la existencia de mecanismos de obtención a largas distancias, lo que implicaría estrategias de movilidad que conllevan rangos de acción amplios; o bien, de rangos acotados y modos de interacción con otros grupos. La fuente más próxima de esta materia prima es El Peceño (Pompei 2019; Salgán y Pompei 2017), localizada en un rango de distancia no local $(82 \mathrm{~km})$. Siguiendo el modelo de aprovisionamiento propuesto por Salgán (2013) para La Payunia, el abastecimiento de obsidiana de El Peceño sería de tipo cíclico directo (Pompei 2019), es decir, sin necesidad de interacción con otros 
grupos, y en relación a incursiones logísticas (Gil 2000). En el registro cerámico observamos la misma tendencia donde la interacción con otros grupos no sería importante (Tabla 6), teniendo en cuenta la baja frecuencia de estilos tecnológicos cerámicos no locales, como Nihuil/Overo y Marrón Pulido (Sugrañes et al. 2020).

La tendencia del conjunto cerámico (Tabla 6) muestra, principalmente, características de una baja movilidad residencial, con la presencia de una alta diversidad tecnológica, a pesar del tamaño pequeño de la muestra. Atributos como el tratamiento de superficie, la diversidad de formas y de estilos tecnológicos locales presentes en el sitio, son muestra de ello. La baja diversidad de grupos químicos en la cerámica (Tabla 6), responde a las expectativas de una baja movilidad residencial: el G5, que es el mayoritario, es considerado local al Monte, área biogeográfica en la que se emplaza LG-1 (Sugrañes et al. 2020).

La baja diversidad de clases artefactuales del conjunto lítico (Tabla 6) puede estar asociada a una baja tasa de depositación de artefactos, lo que apoya la idea de que el sitio haya sido originado durante un único evento de ocupación (véase más arriba). La ausencia de instrumentos (Tabla 6) puede deberse a que estos fueron utilizados y descartados en otros loci.

Las características de baja decoración y el tamaño pequeño de los contenedores (Tabla 6) son atributos vinculados más bien a una mayor movilidad; sin embargo, esto puede deberse a un ajuste y/o selección de las vasijas para una estrategia de transporte de las mismas. Situación que Sugrañes et al. (2020) mostraron para la cuenca del río Atuel, donde esta selección puede haber ocurrido para transportar individualmente vasijas, ya sea para la explotación de recursos en otras áreas o, simplemente, para que el acarreo de estos elementos no conlleve tanto peso (Eerkens 2003, 2012).

Se observa que las variables tecnológicas utilizadas para el análisis indican una tendencia concordante con lo señalado para grupos con movilidad residencial baja (Tabla 6). Si bien algunas de las variables están asociadas a una alta movilidad residencial, estas pueden estar vinculadas a otros tipos de movilidad complementarias, como partidas logísticas (p.e. aprovisionamiento directo de obsidiana, partidas de caza), en cuyo contexto los instrumentos se descartan en el lugar de uso (Binford 1980); lo cual podría explicar también su ausencia en LG-1. Por otra parte, los resultados de los fechados radiocarbónicos y la baja tasa de descarte material evidencian una baja reocupación.

\section{LG-1 en el contexto regional del Atuel Medio}

Para integrar los resultados de los análisis sobre los materiales arqueológicos de LG-1 en la discusión regional, estos fueron comparados con los conjuntos líticos y cerámicos de cuatro sitios cercanos. Estos sitios son El Bosquecillo 3 y 5 (Corbat 2016; Pompei 2019), La Olla (Giardina et al. 2015) y Rincón del Atuel 1 (Gil et al. 2008; 
Sugrañes 2017a) (Figura 1a); en estos dos últimos sitios, los autores distinguieron dos componentes temporales dentro del Holoceno tardío final. La Figura 4 muestra la inserción temporal de estas ocupaciones en el marco de la demografía humana inferida para el sur de Mendoza (Gil et al. 2019), y la Tabla 7 señala las variables analizadas y los valores obtenidos.

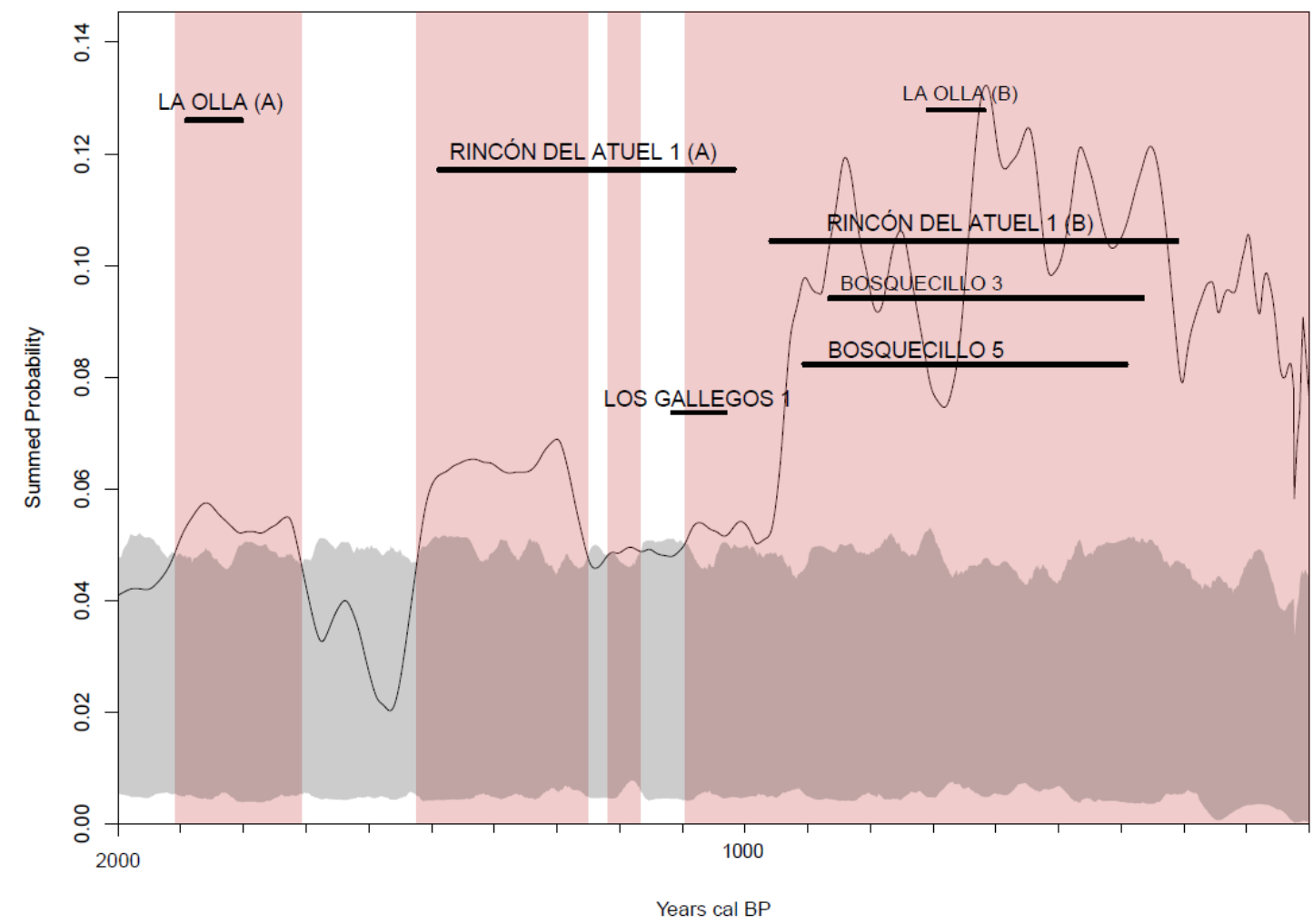

Figura 4. Suma de probabilidades de fechados radiocarbónicos del sur de Mendoza (34 a 37느). Análisis realizado con RCarbon (Bevan y Crema 2018). El área gris señala la variación modelada para crecimiento uniforme; el área salmón señala periodos de crecimiento significativo en la curva empírica.

Sobre la base de 311 fechados radiocarbónicos, obtenidos en 112 sitios arqueológicos, se modeló la suma de probabilidades comparada respecto a un crecimiento teórico uniforme (Bevan y Crema 2018; Gil et al. 2019, 2020). La Figura 4 señala dos escenarios demográficos. El primero, hasta ca. 1000 años cal. AP presenta valores estables, aunque significativamente menores a los que se desarrollan post $c a$. 1000 años cal. AP. La zona "gris" muestra la demografía esperada bajo un modelo uniforme, sin cambios. Las bandas color salmón señalan aquellos momentos con incrementos mayores a los esperados por el modelo uniforme. En el primer escenario, si bien hay algunos pulsos de incremento, estos son breves y de baja densidad. Contrariamente post 1000, todo el periodo posee valores de incremento de densidades y por encima de lo esperado para el modelo uniforme (cf. Crema et al. 2017; Gil et al. 2020). 
Junto a las ocupaciones de LG-1, en el primer escenario se registran las ocupaciones tempranas de RA-1, Rincón del Atuel (A) y La Olla (A). Los otros conjuntos, Rincón del Atuel (B), La Olla (B), El Bosquecillo 3 y El Bosquecillo 5, se registran bajo el escenario post 1000 años cal. AP (Figura 4).

\begin{tabular}{|c|c|c|c|c|c|c|c|}
\hline Variables/Sitios & RA-1 (A) & LG-1 & LO (A) & LO (B) & EB-3 & EB-5 & RA-1 (B) \\
\hline $\begin{array}{l}\text { Componente } \\
\text { temporal }\end{array}$ & $\begin{array}{c}\text { Comp. A } \\
\text { (1500 años } \\
\text { AP) }\end{array}$ & $\begin{array}{l}(1200 \\
\text { años } \\
\text { AP) }\end{array}$ & $\begin{array}{l}\text { Comp. A } \\
\text { (1900 años } \\
\text { AP) (C1- } \\
\text { C2) }\end{array}$ & $\begin{array}{c}\text { Comp. B } \\
\text { (700 años } \\
\text { AP) } \\
\text { (A1-A2) }\end{array}$ & $\begin{array}{c}\text { (748 años } \\
\text { AP) }\end{array}$ & $\begin{array}{c}\text { (762 años } \\
\text { AP) }\end{array}$ & $\begin{array}{l}\text { Comp. B } \\
(1030 \\
\text { años AP) }\end{array}$ \\
\hline $\begin{array}{l}\text { Lapso temporal } \\
(\text { años) (t) }\end{array}$ & 465 & 64 & 69 & 129 & 618 & 832 & 554 \\
\hline N lítico & 301 & 114 & 327 & 195 & 80 & 122 & 2834 \\
\hline $\begin{array}{l}\text { Tasa dep. } \\
\text { lítico/año }\end{array}$ & 0,05 & 0,22 & 0,59 & 0,25 & 0,06 & 0,07 & 0,43 \\
\hline $\begin{array}{l}\text { Índice MP No } \\
\text { local/total MP }\end{array}$ & 0,1 & 0,03 & 0,37 & 0,43 & 0,6 & 0,45 & 0,35 \\
\hline $\begin{array}{l}\text { Índice Etapas } \\
\text { intermedias y } \\
\text { finales/total }\end{array}$ & 0,97 & 1 & 0,95 & 0,98 & 1 & 1 & 0,98 \\
\hline $\begin{array}{l}\text { Reactiv./total } \\
\text { DT }\end{array}$ & 0 & 0 & 0,12 & 0,05 & 0 & 0,05 & 0,002 \\
\hline Instr./total lítico & 0 & 0 & 0 & 0,02 & 0,01 & 0,02 & 0,01 \\
\hline $\begin{array}{l}\text { N Clases } \\
\text { Artefact. }\end{array}$ & 2 & 2 & 2 & 2 & 2 & 3 & 4 \\
\hline $\begin{array}{l}\text { Índice Div. } \\
\text { Clases Artefact. } \\
\text { (Simpson) }\end{array}$ & 0,01 & 0,08 & 0,02 & 0,04 & 0,02 & 0,06 & 0,03 \\
\hline $\begin{array}{l}\text { N Fragmentos } \\
\text { Cerámicos }\end{array}$ & 2 & 21 & 38 & 34 & 3 & 6 & 143 \\
\hline $\begin{array}{l}\text { Tasa dep. } \\
\text { cerámica/año }\end{array}$ & 0,0003 & 0,04 & 0,04 & 0,08 & 0,002 & 0,004 & 0,02 \\
\hline $\begin{array}{l}\text { N Estilos } \\
\text { tecnológicos }\end{array}$ & 1 & 4 & 3 & 2 & - & - & 3 \\
\hline $\begin{array}{l}\text { Índice Div. Est. } \\
\text { Cerámicos } \\
\text { (Simpson) }\end{array}$ & 0 & 0,69 & 0,39 & 0,47 & - & - & 0,15 \\
\hline Lítico/Cerámica & 150,5 & 5,4 & 8,6 & 5,7 & 26,7 & 20,3 & 19,8 \\
\hline
\end{tabular}

Tabla 7. Tendencias de los conjuntos líticos y cerámicos del Monte sur mendocino. Los sitios fueron ordenados temporalmente.

La tasa de depositación de materiales líticos varía entre 0,005 y 0,59 (Tabla 7), presentando LG-1 valores intermedios y similares a LO (B) del período post ca. 1000 AP. La tasa de depositación de materiales cerámicos se encuentra entre 0,0003 y 0,02, y 
registra una tendencia similar en LG-1, con valores intermedios a los sitios cercanos. LG-1 está entre los sitios que tienen la relación más baja de artefactos líticos descartados por cada tiesto cerámico, lo que lo asemeja al sitio La Olla (en ambos conjuntos).

Las materias primas líticas utilizadas son similares $y$, aunque varían en su representación, predominan las rocas silíceas. La obsidiana, de procedencia no local en todos los sitios considerados, tiene una representación de entre el $3 \%$ y $45 \%$. Las ocupaciones pre $1000 \mathrm{AP}$, donde se incluye a LG-1, son inferiores al $37 \%$, mientras que las post 1000 tienen valores superiores que alcanzan el 60 \% (Tabla 7). Esto señala una tendencia regional al incremento en el uso de rocas no locales, post 1000 años AP que, asociado al escenario de incremento poblacional, se interpreta como un incremento en las redes de intercambio regional (Neme 2007).

En LG-1, el índice de diversidad de Simpson para clases artefactuales líticas es mayor que en el resto de los sitios. No existe un sesgo generado por el tamaño de la muestra $\left(\mathrm{r}^{2}=0,1357\right)$. LG-1 junto al resto de los sitios pre 1000 se diferencia de los post 1000 por la ausencia de instrumentos líticos.

Respecto a la talla lítica, las etapas mayormente representadas son las intermedias y finales en todos los sitios; en LG-1, al igual que en EB-3 y EB-5, no se registraron las etapas iniciales (Tabla 7). Lo mismo sucede en los componentes tempranos de RA-1 y $\mathrm{LO}$, donde las dos clases artefactuales representadas en ambos sitios son núcleos y desechos de talla (Tabla 7).

Los estilos tecnológicos cerámicos presentes en los sitios son los mismos, siendo mayoritaria la identificación de estilos locales a este sector de la cuenca del río Atuel (Arbolito y Atuel Cepillado) y, también, de la región altoandina de esta cuenca (Nihuil). Sin embargo, el índice de diversidad de Simpson muestra que LG-1 es el más diverso en cuanto a estilos tecnológicos comparado con los otros sitios. En RA-1 hay un aumento en el $\mathrm{N}$ y en la diversidad de estilos tecnológicos en el componente tardío, a diferencia de $\mathrm{LO}$ en el que, si bien el $\mathrm{N}$ disminuye, el índice de Simpson muestra un aumento en la diversidad.

Los resultados obtenidos del análisis tecnológico, permiten considerar a Los Gallegos 1 como un sitio asociado a grupos humanos con un patrón de movilidad residencial baja y, con un lapso de ocupación breve ( $c a .100$ años) en el que realizaron diversas actividades. Las evidencias muestran que en el sitio se dio un aprovechamiento mayoritario de recursos locales (arcillas, rocas, recursos animales) y el aprovisionamiento cíclico directo de recursos de alta calidad. 


\section{Conclusión}

El área biogeográfica denominada Monte (Neme y Gil 2012) es una de las que cuenta con menor cantidad de trabajos arqueológicos de todas las que constituyen el sur de la provincia de Mendoza. Entender el funcionamiento de los grupos humanos en este espacio, que representa casi la mitad de la superficie de la región, es de suma importancia para entender procesos vinculados al uso de los recursos, el poblamiento de la región, o la llegada de la agricultura al sur de Mendoza, entre otros. Creemos que los resultados presentados en este trabajo nos permiten visualizar con un poco más de claridad el tipo de estrategias empleadas para ocupar estos espacios con recursos animales y vegetales distribuidos homogéneamente, pero con recursos hídricos escasos y localizados.

El análisis conjunto de la tecnología lítica y cerámica permitió indagar acerca de la planificación y las estrategias de movilidad utilizadas por los grupos humanos para explotar recursos alimenticios y materias primas en el desierto de Monte del sur de Mendoza. Las evidencias presentadas y discutidas en función del resto de los sitios del área, sugiere la presencia de grupos móviles, pero de baja movilidad residencial. Como sostiene Kelly (1992), los seres humanos no se hacen sedentarios sino que se "mueven menos". La tecnología de Los Gallegos 1 y sitios aledaños, podría responder al equipamiento de los mismos grupos móviles, pero con patrones de ocupación diferente en distintos loci. Entonces, proponemos que, para el Holoceno tardío final, la movilidad de los grupos humanos habría cambiado hacia una estrategia con menor movilidad residencial, y con un posible componente logístico, el cual implicó algunas modificaciones en las tecnologías implementadas. El caso de LG-1 muestra una ocupación en la que se realizaron múltiples actividades durante un lapso temporal relativamente corto, con respecto a otros sitios contemporáneos, como La Olla y Rincón del Atuel 1, a los cuales se asemeja tecnológicamente.

Consideramos que los resultados del análisis tecnológico de LG-1, señalan rasgos importantes a tener en cuenta en la reconstrucción de los patrones de movilidad y asentamiento de las poblaciones que habitaron el este de la cuenca media del río Atuel; tales patrones, no necesariamente se desprenderían del mero análisis de las evidencias de subsistencia. Igualmente, consideramos que ambos tipos de análisis (tecnológico y de subsistencia) se retroalimentan positivamente y deben estudiarse en conjunto para poder indagar en dicha reconstrucción del pasado. Queda pendiente explicar la ausencia de instrumentos tanto en LG-1, como en los componentes tempranos de RA-1 y LO. Sin embargo, estas tendencias iniciales nos permiten plantear la posibilidad de que hacia $c a .1000$ años AP se puedan haber diversificado las técnicas de explotación de recursos (subsistencia y líticos) y que los instrumentos se hayan utilizado con otros fines (e.g. herramientas de labranza y/o pesca) y en otros loci de ocupación. Futuros trabajos de excavación en este y otros sitios próximos permitirán mejorar nuestra comprensión de los procesos involucrados en la explotación del desierto de Monte en el Centro Oeste Argentino. 
Agradecimientos: Agradecemos al Ing. Luis Gisasola (Gobierno de Mendoza) y a quienes colaboraron con los trabajos de campo. A las y/o los evaluadores quienes con sus aportes mejoraron el presente trabajo. Esta investigación se realizó gracias a dos becas doctorales de CONICET adjudicadas a las autoras y al financiamiento de ANPCyT mediante los proyectos PICT-2016-2667 y PIP-CONICET 2015-2017/ 0342.

\section{Bibliografía citada}

Abraham, M. E.

2000 Geomorfología de la Provincia de Mendoza. Recursos y problemas ambientales de la zona árida. Provincias de Mendoza, San Juan y La Rioja. E.M. Abraham y F.R Martínez (Eds.). Tomo I, Caracterización ambiental: 29-48.

Andrefsy JR., W.

1994 Raw-material availability and the organization of technology. American Antiquity 59 (1): 21-34.

Aragón, E. y N. V. Franco

1997 Características de rocas para la talla por percusión y propiedades petrográficas. Anales del Instituto de la Patagonia (Serie Ciencias Humanas). 25: 87-199.

Arnold, D.

1985 Ceramic Theory and Cultural Process. Cambridge University Press.

Aschero, C.

1975 Ensayo para una clasificación morfológica de artefactos líticos aplicados a estudios tipológicos comparativos. (Informe a CONICET). Manuscrito no publicado, disponible en el IDEVEA-CONICET, San Rafael, Mendoza.

1983 Ensayo para una clasificación morfológica de artefactos líticos aplicada a estudios tecnológicos comparativos. Apéndice A-C. Revisión para la cátedra de Ergología y Tecnología (FFyL, UBA). Manuscrito no publicado, disponible en el IDEVEA-CONICET, San Rafael, Mendoza.

Bamforth, D.B.

1986 Technological Efficiency and Tool Curation. American Antiquity 51 (1): 38-50.

2006 The Windy Ridge quartzite quarry: hunter-gatherer mining land use in the North American Continental Divide. World Archaeology 38 (3): 511-527.

Beck, M.E.

2009 Residential Mobility and Ceramic Exchange: Ethnography and Archaeological. Journal of Archaeological Method and Theory 16(4): 320-356. 
Beck, C., y A.K. Taylor, G. T. Jones, C.M. Fadem, C. R. Cook, S. A. Millward 2002 Rocks are heavy: transport costs and Paleoarchaic quarry behavior in the Great Basin. Journal of Anthropological Archaeology 21: 481-507.

Bettinger, R. y J. Eerkens

1999 Point Typologies, Cultural Transmission, and the Spread of Bow-and-Arrow Technology in the Prehistoric Great Basin. American Antiquity 64 (2): 231-242.

Bettinger R. L., y B. Winterhalder, R. McElreath

2006 A simple model of technological intensification. Journal of Archaeological Science 33: 538-545.

Bevan, A. y E.R. Crema,

2018 rcarbon v1.2.0: Methods for calibrating and analyzing radiocarbon dates. https:/ /CRAN.R-project.org/package=rcarbon

Binford, L.

1980 Willow smoke and dog's tails: hunter-gatherer settlement system and archaeological site formation. American Antiquity 45 (1): 4-20.

Bishop, R., y R.L. Rands, G.R. Holley

1982 Ceramic compositional analysis in archaeological perspective. Advances in Archaeological Method and Theory 7:275-330, M. Schiffer Ed. Academic Press, New York.

Bright I. R., y A. Ugan.

1999 Ceramics and Mobility: Assessing the Role of Foraging Behavior and Its Implications for Culture-History. Utah Archaeology 12:17-29.

Cabrera, A. L.

1971 Fitogeografía de la República Argentina. Boletín de la Sociedad Argentina de Botánica 14: $1-42$.

Capitanelli, R.

1972 Geomorfología y Clima de la provincia de Mendoza. Boletín de la Sociedad Argentina de Botánica: 15-48.

Carr, P.

1994 The organization of technology: impact and potential. The Organization of North American Prehistoric Chipped Stone Toll Technologies. P. Carr (ed.). 1-8. International Monographs in Prehistory, Archaeological Series 7.

Close, A.E.

2000 Reconstructing movement in prehistory. Journal of Archaeological Method and Theory 7: 49-77. 
Corbat, $\mathrm{M}$.

2016 Variabilidad ambiental y sociocultural en la explotación de peces en el centro-occidente argentino: Una evaluación zooarqueológica. Tesis Doctoral inédita. Facultad de Filosofía y Letras, Universidad de Buenos Aires. Buenos Aires.

Cortegoso, V., y G. Neme, M. Giesso, V. Durán, A. Gil

2012 El uso de la obsidiana en el sur de Mendoza. Paleoecología humana en el sur de Mendoza: perspectivas arqueológicas. G. Neme y A. Gil (Comps.). 181-212. Sociedad Argentina de Antropología. Buenos Aires.

Crema, E. R. y A. Bevan, S. Shennan

2017 Spatio-Temporal Approaches to Archaeological Radiocarbon Dates. Journal of Archaeological Science. 87, 1-9.

Durán, V., y M. Giesso, M. Glascock, G. Neme, A. Gil, L. Sanhueza

2004 Estudio de fuentes de aprovisionamiento y redes de distribución de obsidiana durante el Holoceno tardío en el sur de Mendoza (Argentina). Estudios Atacameños 28: 25-43.

Eerkens, J.

2003 Residential mobility and pottery use in the Western Great Basin. Current Anthropology 44(5): 728-738.

2012 A model for predicting economic interaction in arid lands and an evaluation in Eastern California based on brownware ceramics. D. Rhode (ed.). Meet at the Margins. Prehistoric Cultural Interaction in the Intermountain West. 229-245. Utah Press.

Ericson, J.E.

1984 Toward the analysis of lithic production systems. Prehistoric quarries and lithic production. J.E. Ericson, y B.A. Purdy (eds.). 1-9. Cambridge University Press. Cambridge.

Falabella, F., y L. Sanhueza, G. Neme, H. Lagiglia

2001 Análisis comparativo de cerámica Aconcagua entre Chile y Argentina. Relaciones de la Sociedad Argentina de Antropología XXVI: 193-214.

Feely, A. y N. Ratto

2013 Cálculo del Número Mínimo de Vasijas y Recolección Superficial: Criterios Metodológicos y Análisis de Casos del Oeste Tinogasteño (Catamarca). Andes 24: 425-445.

Foley, R.

1981 Off-Site Archaeology and Human Adaptation in Eastern Africa. An Analysis of Regional Artefact Density in the Amboseli, Southern Kenia. Cambridge Monographs in African Archaeology 3. BAR International Series 97. Oxford.

Franchetti, F.

2019 Hunter-gatherer adaptation in the deserts of northern Patagonia. Tesis doctoral inédita. The Dietrich School of Arts and Sciences. University of Pittsburgh. 
Franco, N. V.

2002 Estrategias de utilización de recursos líticos en la cuenca superior del río Santa Cruz (Argentina). Tesis doctoral inédita. Facultad de Filosofía y Letras, Universidad de Buenos Aires. Buenos Aires.

2004 La Organización Tecnológica y el uso de escalas espaciales amplias. El caso del sur y oeste de Lago Argentino. Temas de Arqueología, Análisis lítico. A. Acosta, D. Loponte y M. Ramos (eds.). 101-144. Buenos Aires.

Giardina, M.

2010 El aprovechamiento de la avifauna entre las sociedades cazadoras-recolectoras del sur de Mendoza, un enfoque arqueozoológico. Tesis Doctoral inédita. Facultad de Ciencias Naturales y Museo, Universidad Nacional de La Plata. La Plata.

Giardina, M. y M. Corbat, E. Peralta, G. Cochero, F. Franchetti, M.L. Salgán, A. Gil

2015 El registro arqueológico en el sitio La Olla (San Rafael, Mendoza): Implicaciones para las ocupaciones humanas en el valle medio del río Atuel. Revista del Museo de Antropología 8 (1): 51-66.

Giesso, M., y V. Durán, G.A. Neme, M.D. Glascock, V. Cortegoso, A.F. Gil, L. Sanhueza 2011 A study of obsidian source usage in the central Andes of Argentina and Chile. Archaeometry 53 (1): 1-21.

Gil, A. F.

1997-1998 Cultígenos prehispánicos en el sur de Mendoza. Discusiones en torno al límite meridional de la agricultura andina. Relaciones de la Sociedad Argentina de Antropología XXIIXIII: 295-313. 2004-2006.

2006 Arqueología de La Payunia. BAR International Series 1477. Inglaterra.

Gil, A. F. y G. A. Neme

2010 Registro arqueológico en la cuenca media del Atuel: viejos y nuevos problemas; viejos y nuevos datos. M. Zárate, A. Gil y G. Neme (Eds.). Condiciones Paleoambientales y ocupaciones humanas durante la transición Pleistoceno-Holoceno de Mendoza. 239-276. Sociedad Argentina de Antropología. Buenos Aires.

Gil, A. F., y M. Giardina, G. A. Neme, A. Ugan

2014 Demografía humana e incorporación de cultígenos en el Centro Oeste Argentino: explorando tendencias en las fechas radiocarbónicas. Revista Española de Antropología Americana 44 (2): 523-553.

Gil, A. F. y G. A. Neme, A. Hernández, P. Novellino, M. Giardina, M.L. Salgán, H. Tucker, E. Albarrán

2008 Rincón del Atuel-1 (San Rafael, Mendoza): Evidencias arqueológicas e implicancias regionales. Intersecciones en Antropología 9: 113-132. 
Gil A. y G. Neme, R. Tykot, P. Novellino, V. Cortegoso, V. Durán

2009 Stable Isotopes and Maize Consumption in Central Western Argentina. International Journal of Osteoarchaeology 19: 215 - 236.

Gil, A. F. y G. A. Neme, A. Ugan, R. H. Tykot.

2011 Oxygen isotopes and human residential mobility in central western Argentina. International Journal of Osteoarchaeology

DOI: $10.1002 /$ oa.1304

Gil, A. y N. Sugrañes, A. Acevedo, G. Neme, M.L. Salgán, M. Giardina, H. Tucker, D. Fiore, V. Seitz, M. P. Pompei, M. Ayala.

2019 Biogeografía Humana y Tendencia Demográfica en el Monte Nordpatagónico. Una aproximación arqueológica desde El Corcovo (SE de Mendoza). Revista del Museo de Antropología 12 (2): 23-40.

Gil A. y R. Villalba, F. R. Franchetti, C. Otaola, C. C. Abbona, E. A. Peralta, G. Neme.

2020 Between Foragers and Farmers: Climate Change and Human Strategies in Northwestern Patagonia. Quaternary. 3, 17. doi:10.3390/quat3020017

Glascock, M. D.

1992 Characterization of Archaeological Ceramics at MURR by Neutron Activation Analysis and Multivariate Statistics. H. Neff (ed.). Chemical Characterization of Ceramic Pastes in Archaeology. 11-26. Madison, Prehistory Press.

Hitchcock, R. K.

1987 Sedentism and site structure: organzational change in Kalahari Basarwa residential locations. Method and Theory for Activity Area Research. S. Kent (ed). 374-423. New York: Columbia Univ. Press

Hogg, A. y Q. Hua, P. Blackwell, M. Niu, C. Buck, T. Guilderson, T. Heaton, H. Palmer, P. Reimer, R. Reimer, C. Turney, S. Zimmerman.

2013 SHCal 13 Southern Hemisphere Calibration, 0-50,000 Years cal BP. Radiocarbon 55 (4): 1889-1903.

Hughes, R. E.

2011 Sources of Inspiration for Studies of Prehistoric Resource Acquisition and Materials Conveyance in California and the Great Basin. Perspectives on Prehistoric Trade and Exchange in California and the Great Basin. Hughes, R. E. (ed.). 1-21. The University of Utah Press, Salt Lake City. Utah.

Ingbar, E.

1994 Lithic Material Selection and Technological Organization. The organization of North American prehistoric chipped stone Technologies. P. Carr (ed.). 45-56. International Monographs in Prehistory. Archaeological Series 7. Michigan. 
Jones, G.T., y C. Beck, E.E. Jones, R.E. Hughes

2003 Lithic Source Use and Paleoarchaic Foraging Territories in the Great Basin. American Antiquity 68 (1): 5-38.

Kelly, R.

1983 Hunter-Gatherer mobility strategies. Journal of Anthropological Research 39: 277-306.

1988 The three sides of a Biface. American Antiquity 53 (4): 717-734.

1992 Mobility/Sedentism: Concepts, Archaeological Measures, and Effects. Annual Review of Anthropology 21: 43-66.

Kuhn, S.L.

1992 On planning and curated technologies in the Middle Paleolithic. Journal of Anthropological Research 48 (3): 185-214.

2004 Upper Paleolithic raw material economies at Üçagızlı cave, Turkey. Journal of Anthropological Archaeology 23: 431-448.

Lagiglia, $\mathrm{H}$.

1968 Secuencias culturales del Centro-Oeste argentino: Valles del Atuel y del Diamante. Revista Científica de Investigaciones del Museo de Historia Natural de San Rafael I (4): 159-176.

1977 Arqueología y ambiente natural de los valles del Atuel y del Diamante. 2 tomos. Tesis Doctoral Inédita. Facultad de Ciencias Naturales y Museo, Universidad Nacional de La Plata.

1997 Arqueología de cazadores-recolectores cordilleranos de altura. Ediciones Ciencia y Arte. San Rafael.

1999 Nuevos fechados radiocarbónicos para los agricultores incipientes del Atuel. Actas del XII Congreso Nacional de Arqueología Argentina. 239-250. La Plata.

2002 Arqueología prehistórica del sur mendocino y sus relaciones con el Centro Oeste Argentino. Entre Montañas y Desiertos: Arqueología del Sur de Mendoza. A. Gil y G. Neme (eds.). 43-64. Sociedad Argentina de Antropología. Buenos Aires.

Llano, C.

2011 Aprovechamiento de los Recursos vegetales entre las sociedades cazadoras-recolectores del Sur de Mendoza. Tesis Doctoral inédita. Universidad Nacional del Comahue. Neuquén.

Mares, M., y J. Morello, G. Goldstein

1985 The Monte desert and other subtropical semi-arid biomes of Argentina, with comments on their relation to North American arid areas. Hot Deserts and Arid Shrublands. M. Evenari, I. Noy-Meir, y D.W. Goodall (eds.). 203-237. Elsevier Science. Amsterdam.

Marsh, E.

2017 La fecha de la cerámica más temprana en los Andes sur. Una perspectiva macrorregional mediante modelos bayesianos. Revista del Museo de Antropología, Suplemento Especial 1: 83-94. 
Meltzer, D.

1989 Was Stone Exchange Among Eastern North American Paleoindians?. Eastern Paleoindian lithic resource use. C. Ellis y J. Lothrop (ed.). 11-39. Westview Press. Colorado.

Morgan, C.

2009 Climate change, uncertainty and prehistoric hunter-gatherer mobility. Journal of Anthropological Archaeology 28: 382-396.

Nelson, M. C.

1991 The Study of Technological Organization. Archaeological Method and Theory. M. Schiffer (ed.). 3: 57-100. University of Arizona Press. Tucson.

Neme, G.

2007 Cazadores Recolectores de Altura en Los Andes Meridionales: El Alto Valle del Atuel (Mendoza, Argentina). BAR Internacional Series 1591. Inglaterra.

Neme, G. y A. Gil

2008 Biogeografía humana en los Andes meridionales: tendencias arqueológicas en el sur de Mendoza. Chungara 40 (1): 5-18.

2012 El registro arqueológico del sur de Mendoza en perspectiva biogeográfica. Paleoecología humana en el sur de Mendoza: perspectivas arqueológicas. G. Neme y A. Gil (comp.). 255-280. Sociedad Argentina de Antropología. Buenos Aires.

Neme, G. y A. Gil, C. Otaola, M. Giardina,

2013 Resource exploitation and human mobility: Trends in the archaeofaunal and isotopic record from central western Argentina. International Journal of Osteoarchaeology 25(6): 866-876.

Orton, C., y P. Tyers, A. Vince

1993 La cerámica en Arqueología. Barcelona. Ed. Crítica.

Ots, M. J.

2008 Estudio de Alteraciones Provocadas por Laboreo Agrícola sobre Conjuntos Cerámicos en Agua Amarga (Tupungato, Mendoza, Argentina). Chungará, Revista de Antropología Chilena 40 (2): 145-160.

Pallo, M. C. y L. A. Borrero

2015 ¿Intercambio o Movilidad?: Una Evaluación Sobre el Uso de Escalas de Análisis Espaciales y Curvas de Declinación en Patagonia Centro-Meridional (Argentina). Latin American Antiquity 26 (3): 287-303. 
Peralta, E.A.

2019 Demografía Humana, Dieta y Actividad en los Límites de la Dispersión Agrícola: Tendencias Bioarqueológicas en el Sur de Mendoza a finales del Holoceno Tardío. Tesis doctoral inédita. Facultad de Filosofía y Letras. Universidad de Buenos Aires.

Pompei, M. P.

2019 Organización de la tecnología lítica en la cuenca del río Atuel (sur de la provincia de Mendoza) durante el Holoceno tardío. Tesis doctoral inédita. Facultad de Ciencias Naturales y Museo, Universidad Nacional de La Plata, La Plata.

Renfrew, C.

1977 Alternative models for exchange and spatial distribution. Exchange Systems in Prehistory. T. Earle y J. Ericson (ed.). 71-90. Academic Press. New York.

Rye, O.

1988 Manual on Archaeology 4. Pottery Technology. Principles and Reconstruction. Australian National University, Taraxacum, Washington.

Roig, F. A.

1972 Bosquejo fisionómico de la vegetación de la provincia de Mendoza. Boletín de la Sociedad Argentina de Botánica: 49-80.

Salgán, M. L.

2013 Organización tecnológica y biogeografía humana en La Payunia, sur de la Provincia de Mendoza. Tesis Doctoral inédita. Facultad de Ciencias Naturales y Museo, Universidad Nacional de La Plata. La Plata.

Salgán, M. L., y R. Garvey, G. A. Neme, A. F. Gil, M. Giesso, M. Glascock, V. Durán

2015 Las Cargas: Characterization of a Southern Andean Obsidian Source and Its Prehistoric Use. Geoarchaeology. An International Journal 30 (2): 139-150.

Salgán, M. L., y S. Paulides, V. Cortegoso

2012 Rocas, rangos de acción y biogeografía humana en el sur de Mendoza. Paleoecología humana en el sur de Mendoza: perspectivas arqueológicas. G. Neme y A. Gil (comps.). 157-180. Sociedad Argentina de Antropología. Buenos Aires.

Salgán, M. L. y M. P. Pompei

2017 Fuente de obsidiana El Peceño: primeros resultados de su abordaje tecnológico, geoquímico y espacial. Revista del Museo de Antropología, Suplemento Especial 1: 51-58.

Sepúlveda, E., y F. Carpio, M.C. Regairaz, M. Zárate, J.C.M. Zanettini.

2000 Hoja Geológica 3569-II, San Rafael, provincia de Mendoza. Instituto de Geología y recursos minerales, Servicio Geológico Minero Argentino, Boletín 321. Buenos Aires. 
Shepard, A.

1985 [1956] Ceramics for the Archaeologist. Publication 609. Carnegie Institution of Washington. Washington D.C,

Sherwood, S.C.

2001 Microartifacts. Earth sciences and archaeology. 327-352. P. Goldberg, V. Holliday y C.R. Ferring (eds.). Kluwer Academic/Plenum Publisher, New York.

Shott, M.

1986Technological organization and settlement mobility: an ethnographic examination. Journal of Anthropological Research 4 (2): 15-51.

Simms, S., y J. Bright, A. Ugan

1997Plain-ware ceramics and Residential Mobility: A case study from the great Basin. Journal of Archaeological Science 24: 779-792.

Stuiver, M. y P.J Reimer, R.W. Reimer

2020CALIB 7.1 [WWW program] at http:/ / calib.org

Sugrañes, N.

2011 Tecnología Cerámica y Estrategias de Movilidad entre Cazadores Recolectores de Altura. El caso del sitio Valle Hermoso 1 (Malargüe, Mendoza). Intersecciones en Antropología. 12: 155-166.

2017a La tecnología cerámica y su relación con las estrategias de subsistencia y movilidad de poblaciones humanas en la cuenca del Atuel (sur de Mendoza), durante el Holoceno tardío. Tesis doctoral inédita. Facultad de Ciencias Sociales, Universidad del Centro de la Provincia de Buenos Aires. Olavarría.

2017b Análisis de Formas sobre Vasijas Enteras de Museos del sur de Mendoza. Revista del Museo de Antropología 10 (1): 37-42. UNC.

2019 Diversidad Cerámica del Sur De Mendoza. Discutiendo Tipologías. Relaciones de la Sociedad Argentina de Antropología XLIV (1): 57-76.

Sugrañes, N. y F. Franchetti

2012 Antecedentes, problemas y perspectivas del análisis cerámico en el sur de Mendoza. Una puesta al día. Paleoecología Humana en el Sur de Mendoza: Perspectivas Arqueológicas. G. Neme y A. Gil (Comp.). 229-253. Buenos Aires, Sociedad de Antropología Argentina.

Sugrañes, N. y G. Neme, M. D. Glascock, J. Eerkens, B. Lee MacDonald 2020 Pottery conveyance in North Patagonia, Argentina: Implications for human mobility across the region. Journal of Archaeological Science 114. 
Torrence, R.

1989 Tools as optimal solutions. Time, energy and stone tools. R. Torrence (ed.).1-6. Cambridge University Press. Cambridge. 